\title{
Comparison of GAN, SIC, SI Technology for High Frequency and High Efficiency Inverters
}

\author{
Sai Kiran Pullabhatla ${ }^{1,}$, Phaneendra Babu Bobba $^{1}$, Satyavani Yadlapalli ${ }^{1}$ \\ ${ }^{1}$ Department of Electrical Engineering, GRIET, Hyderabad, Telangana, India.
}

\begin{abstract}
Power semiconductor devices plays a major role in efficient power conversion. As we have Silicon (Si), Silicon Carbide ( $\mathrm{SiC}$ ) and Gallium Nitride $(\mathrm{GaN})$ based power devices, GaN technologies are ideal for working in high frequency power electronic systems (in $\mathrm{MHz}$ ). Because the $\mathrm{GaN}$ has superior electron mobility and bandgap than the $\mathrm{SiC}$ and $\mathrm{Si}$ it has superior characteristics like low conduction losses, high switching rate so that there is better power efficiency than $\mathrm{SiC}$, Si based inverter. Here we are using the Gan based High-Electron-Mobility Transistor (HEMT) and SiC and Si based mosfet in the inverter. The proposed inverter of different topologies is designed to transfer the power at $>1 \mathrm{MHz}$ range. Comparison of the three different switches is done by the output power and the efficiency of the inverter. This paper presents the SPICE simulation results of the class $d$ and class e inverter of output power $1 \mathrm{KW}$.
\end{abstract}

\section{Introduction}

Inverters are most important in power conversion of DC to $\mathrm{AC}$ as they consist of the solid state devices such as $\mathrm{Si}, \mathrm{SiC}$, $\mathrm{GaN}$ based mosfet. Based on the material properties different devices used in inverter has different applications such as $\mathrm{Si}$ based devices in power frequencies and $\mathrm{SiC}$ and $\mathrm{GaN}$ based devices in high frequency applications such as wireless power transfer in medical and electric vehicles. Silicon band gap (the gap between the valence and conduction bands) is too small and is the energy required to excite an electron from the valence to conduction band. Silicon's band gap is around $1.1 \mathrm{eV}$, whereas the $\mathrm{GaN}$ band gap is around $3.4 \mathrm{eV}$ (depending on temperature) and the band gap for the $\mathrm{SiC}$ is $3.25 \mathrm{eV}$. Therefore for high power transistors, GaN is the clear winner due to its high efficiency. The following Table1 shows the electron band gap and different properties of the devices.

Table 1: Different Properties of Elements

\begin{tabular}{|l|l|l|l|l|}
\hline $\begin{array}{l}\text { Electrical } \\
\text { Property }\end{array}$ & SI & SIC & GAN & UNITS \\
\hline Band Gap & 1.1 & 3.26 & 3.44 & $\mathrm{eV}$ \\
\hline $\begin{array}{l}\text { Thermal } \\
\text { Conduction }\end{array}$ & 1.5 & 3.7 & 1.3 & $\mathrm{~W} / \mathrm{cm} . \mathrm{K}$ \\
\hline Electron Mobility & 1300 & 900 & $\begin{array}{l}900- \\
1200\end{array}$ & $\mathrm{Cm}^{2} / \mathrm{V} . \mathrm{s}$ \\
\hline $\begin{array}{l}\text { Electron } \\
\text { Saturation } \\
\text { Velocity }\end{array}$ & 10 & 22 & 25 & $\left(10^{6}\right) \mathrm{cm} / \mathrm{sec}$ \\
\hline \begin{tabular}{l} 
Critical Field \\
\hline
\end{tabular} & 0.3 & 3 & 3.5 & $\left(10^{6}\right) \mathrm{V} / \mathrm{cm}$ \\
\hline
\end{tabular}

For high frequency operation, the electron saturation and the electron mobility should be high as from the table, GaN is more than the $\mathrm{SiC}$ and Si. Critical field is the most important property as it allows the device to operate at high voltage breakdown voltage and low leakage currents which is less for $\mathrm{Si}$ and high for $\mathrm{GaN}$ and $\mathrm{SiC}$. High thermal conductivity for $\mathrm{SiC}$ gives the device to operate at high temperature than $\mathrm{GaN}$ and $\mathrm{Si}$. Here we are using $\mathrm{GaN}$ HEMT switch of GAN SYSTEMS GS66504B and SiC switch of UNITEDSIC UF3C065080K3S and Si switch of INFINEON TECHNOLOGIES IPD65R420CFD. The following Fig. 1 shows the basic structures of devices.

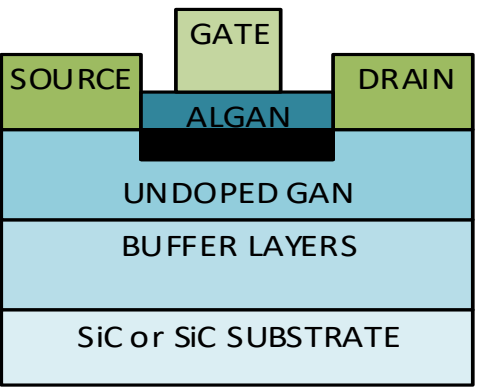

Fig 1(a): Structure of GaN HEMT.

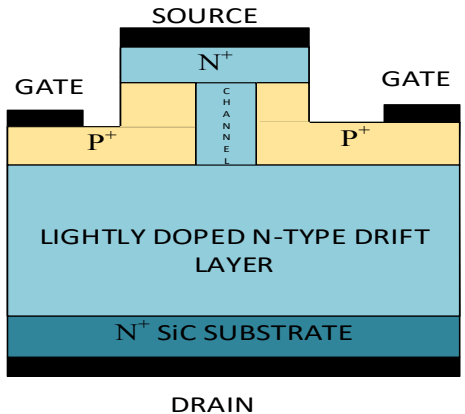

Fig 1(b): Structure of SiC mosfet. 


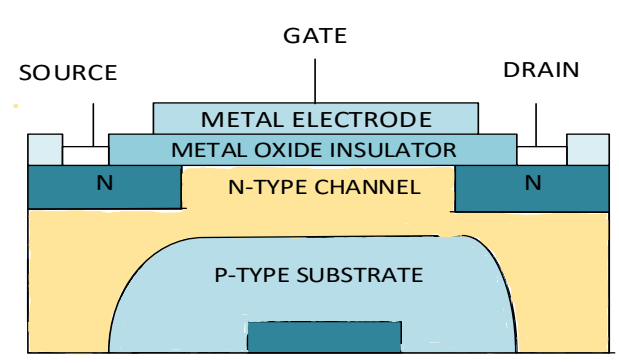

Fig 1(c): Structure of Si mosfet.

As from the above Figs. you can see that the band gap is more for $\mathrm{GaN}$ and $\mathrm{SiC}$ rather than $\mathrm{Si}$. The wide band gap of $\mathrm{GaN}$ and $\mathrm{SiC}$ device produces high power output at high frequency operation with more efficiency than the Si device. The comparison of different topologies of inverters is done by taking a fixed voltage breakdown of the GaN, $\mathrm{SiC}$ and $\mathrm{Si}$ devices. The following Table 2 shows the parameters of the devices.

Table 2: Parameters of the devices Gan, Sic, Si.

\begin{tabular}{|l|l|l|l|}
\hline $\begin{array}{l}\text { PARA-- } \\
\text { METERS }\end{array}$ & $\begin{array}{l}\text { GaN } \\
\text { (GS66506T) }\end{array}$ & $\begin{array}{l}\text { SiC } \\
\text { (UF3C065080K3S) }\end{array}$ & $\begin{array}{l}\text { Si (IPD65- } \\
\text { R420CFD) }\end{array}$ \\
\hline $\mathrm{V}_{\mathrm{DS}}$ & $650 \mathrm{~V}$ & $650 \mathrm{~V}$ & $650 \mathrm{~V}$ \\
\hline $\mathrm{V}_{\mathrm{GS}}$ & -10 to $7 \mathrm{v}$ & -25 to $25 \mathrm{v}$ & 0 to $10 \mathrm{v}$ \\
\hline $\mathrm{R}_{\mathrm{DS}(\mathrm{ON})}$ & $0.01 \Omega$ & $0.01 \Omega$ & $0.42 \Omega$ \\
\hline $\mathrm{R}_{\mathrm{G}}$ & $1.1 \Omega$ & $4.5 \Omega$ & $4 \Omega$ \\
\hline $\mathrm{I}_{\mathrm{D}}$ & $22.5 \mathrm{~A}$ & $31 \mathrm{~A}$ & $8.7 \mathrm{~A}$ \\
\hline $\mathrm{C}_{\mathrm{OSS}}$ & $49 \mathrm{pF}$ & $104 \mathrm{pF}$ & $45 \mathrm{pF}$ \\
\hline $\mathrm{T}_{\mathrm{R}} \& \mathrm{~T}_{\mathrm{F}}$ & $4.9 \& 3.4 \mathrm{~ns}$ & $14 \& 11 \mathrm{~ns}$ & $7 \& 8 \mathrm{~ns}$ \\
\hline
\end{tabular}

The following Fig.2 shows the different types of devices based on the Comparison of output power and the frequency. In this paper we are going to implement a singlephase $\mathrm{H}$-bridge class $\mathrm{d}$ inverter using the wide band gap devices of $\mathrm{GaN}$ and $\mathrm{SiC}, \mathrm{Si}$ and following for the class e inverter using the same devices.

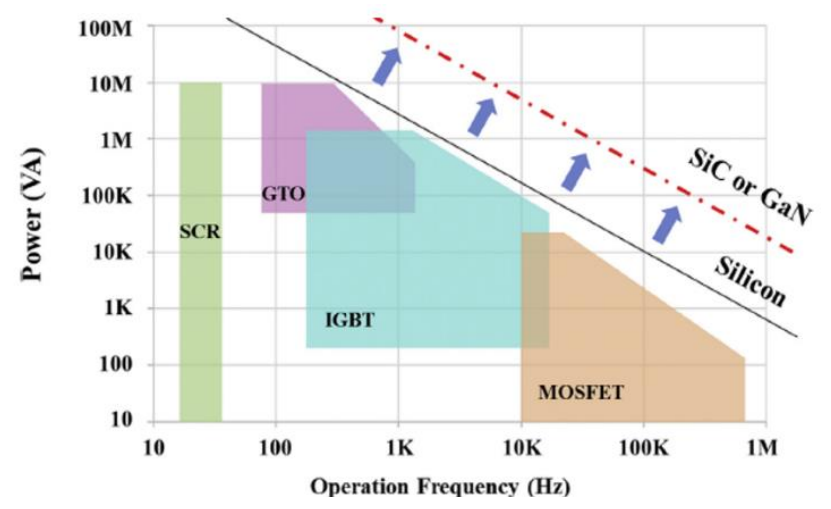

Fig 2: Comparison of different types of devices. [8]

These devices produce high efficiency inverters due to the higher breakdown voltage, lower input and output capacitances, and lower drain-source on-resistance. The Silicon Carbide (SiC) MOSFET and enhancement-mode Gallium Nitride (GaN) FET are the WBG devices which are used in high frequency applications i.e in multi-MHZ inverters.

The inverters have wide range of applications in automobile industry and are creating a change of positivity in the electric vehicles. Electric vehicles require more output power so as to deliver and the inverters which are proposed in this literature are quite same as the requirement of it [7][8]. The charging of the electric vehicles is done mainly through the WPT (Wireless Power Transfer) which is more comfortable than the conventional charging stations [6] and for that WPT these inverters are used for their efficiency. There are so many types of amplifiers which are used around the world like class d, class e, class $\mathrm{e}^{2}$, class ef, class f, class $\Phi$, class f $^{2}$ and so on. Each converter has its frequency range and the power output of the converter. There are so many converters for different applications and mostly selected converters are used. In recent days, one type converter is used to drive the switch so that the efficiency and the power output and the quality of the converters and in nearby future, we are going to implement all types of inverters and compare the power efficiency.

There are two types of switching techniques in any converter design hard switching and soft switching. Hard switching is one which refers to the turn on-off of the switch based on the relationship of the current and voltages, during the on-off transitions of the switch voltage and current of the switch occurs at the drain and source side where the switching noise and losses are produced. In recent days, the applications are based on the high switching frequencies which produce more switching losses as result of increase in the junction temperatures so in order to reduce the switching losses soft switching techniques are implemented. In this method, the addition of the LC parameters to the circuit tends the circuit to operate in the safe way and reduce the switching losses and the conduction losses. In this soft switching i.e Zero Voltage Switching (ZVS), the switch will be in on state when the voltage applied to switch is zero which reduce the transition time of the voltage and current in on state and the reduce the losses in the switch. By the zvs the operation only the turn losses are eliminated.

A $13.56 \mathrm{MHz}$ zvs class d using dynamic dead time is presented in the [1] which is limited to the less power output and in the most of the papers, hardly trying to implement a power output $>1 \mathrm{kw}$. Regarding the class e inverter, so many converters are proposed with more output power and the efficiency is little less than which we have gained. In this paper, we are going to implement zvs class $\mathrm{d}$ and zvs class e inverter which operates in $\mathrm{MHz}$ frequency with a power output of $>1 \mathrm{kw}$. Both the class $d$ and class $e$ inverter simulation are done in the LTPSPICE software simulation.

\section{Analysis of a Class D and Class $E$ Inverter}

Most of the modern-day electronics are depending upon the zvs and zcs based inverters for the better optimization. 
In this section the zvs based class $d$ and class e inverter are presented in detail with the simulation results. For the applications of the electric vehicles which are having frequency of operation in $\mathrm{MHz}$ and the power output of the $>1 \mathrm{kw}$ which is clear region of the type of class $\mathrm{d}$ and class e inverter as they fall in this category and also produces the greater efficiency which is an advantage for wpt applications.

\subsection{Comparison of Devices using ZVS Class D Inverter Topology}

In this part we are going to see the Comparison of different devices of a class $d$ inverter topology. By comparing the inverters with the parameter of output power and efficiency. The class d topology is done using a H-bridge inverter. Class $\mathrm{d}$ triggering is done through unipolar switching and bipolar switching. In unipolar type of triggering, two switch's which conduct at a time are triggered with one signal which is generated by the carrier wave generator whereas in the bipolar independent triggering of switch will be done. As efficiency is criteria, we are going implement unipolar type of triggering method and it also reduces the electro-magnetic interference (EMI). We are going to implement a singlephase H-bridge inverter using the unipolar switching technique. The Fig. 3 shows the class H-bridge inverter.

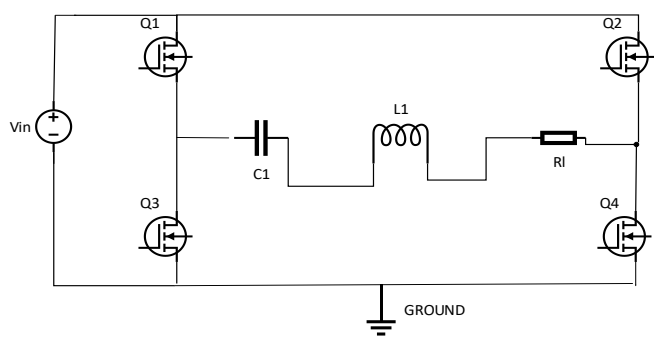

Fig 3: Class d h-bridge inverter using different type of technologies. [1]

In this the inverter consists of 4 mosfet's and the series $\mathrm{RLC}$ resonance circuit in which Resistor $(\mathrm{Rl})$ is taken as load and, Inductor (L1) and capacitor (C1). The supply to the circuit is given through a DC voltage. The following Table 3 gives the input circuit parameters of the inverter.

Table 3: Input parameters of class $\mathrm{d} h$ bridge inverter.

\begin{tabular}{|l|l|l|}
\hline PARAMETERS & VALUE & DESCRIPTION \\
\hline $\mathrm{V}_{\mathrm{dc}}$ & $150 \mathrm{~V}$ & Input de voltage \\
\hline $\mathrm{F}_{\mathrm{SW}}$ & $13.56 \mathrm{MHz}$ & $\begin{array}{l}\text { Switching } \\
\text { frequency }\end{array}$ \\
\hline $\mathrm{F}_{\mathrm{O}}$ & $13.56 \mathrm{MHz}$ & Output frequency \\
\hline $\mathrm{R}_{\mathrm{L}}$ & $11.5 \mathrm{ohms}$ & Load Resistor \\
\hline $\mathrm{L} 1$ & $1.406 \mu \mathrm{H}$ & Inductor \\
\hline $\mathrm{C} 1$ & $98 \mathrm{pf}$ & Capacitor \\
\hline
\end{tabular}

The circuit operates in two modes of operation (i.e) when the switch Q1 \& Q4 are triggered and switches Q2 \&
Q4 are remained in the off position during positive half cycle and during negative half cycle, the switches Q3 \& Q2 are in triggered and the remaining two switches Q1 \& Q2 are kept in off position. The following Fig. 4 shows the modes of operation.

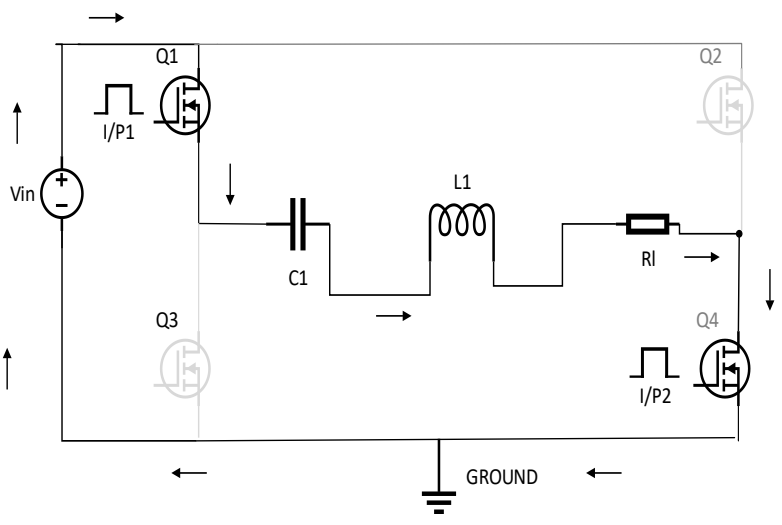

Fig 3(a): During the positive half cycle.

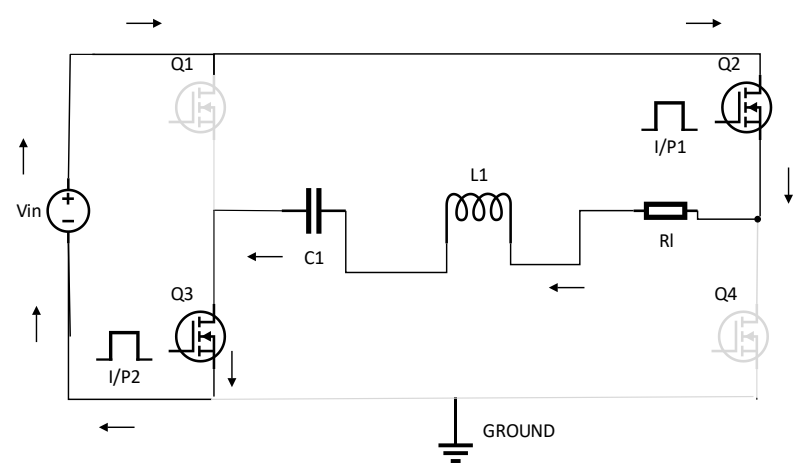

Fig 3(b): During the negative half cycle.

The Fig. 7 shows the voltage and current across the different switch's (GaN, SiC, Si) and the output voltage and output current. The Figs. show the voltage and current at the switch Q1 and Q2 because remaining switches are same (i.e) voltage and current of switch Q4 is same as Q1 and the same for the switch Q3 is as Q2. The following Table 4 shows the values of the voltage and currents at the different points in the circuit of class d inverter for different switches of $\mathrm{GaN}, \mathrm{SiC}, \mathrm{Si}$.

Table 4: Voltage and current at different points of the inverter.

\begin{tabular}{|l|l|l|l|}
\hline PARAMETER & SI & SIC & GAN \\
\hline $\begin{array}{l}\text { VOLTAGE OF } \\
\text { SWITCH Q1 }\end{array}$ & $150 \mathrm{~V}$ & $150 \mathrm{~V}$ & $150 \mathrm{~V}$ \\
\hline $\begin{array}{l}\text { VOLTAGE OF } \\
\text { SWITCH Q2 }\end{array}$ & $150 \mathrm{~V}$ & $150 \mathrm{~V}$ & $150 \mathrm{~V}$ \\
\hline $\begin{array}{l}\text { CURRENT OF } \\
\text { SWITCH Q1 }\end{array}$ & $39 \mathrm{~A}$ & $35 \mathrm{~A}$ & $46 \mathrm{~A}$ \\
\hline $\begin{array}{l}\text { CURRENT OF } \\
\text { SWITCH Q2 }\end{array}$ & $39 \mathrm{~A}$ & $35 \mathrm{~A}$ & $46 \mathrm{~A}$ \\
\hline $\begin{array}{l}\text { OUTPUT } \\
\text { VOLTAGE }\end{array}$ & $150 \mathrm{~V}$ & $150 \mathrm{~V}$ & $150 \mathrm{~V}$ \\
\hline $\begin{array}{l}\text { OUTPUT } \\
\text { CURRENT }\end{array}$ & $18.26 \mathrm{~A}$ & $16.4 \mathrm{~A}$ & $15 \mathrm{~A}$ \\
\hline
\end{tabular}


From the values of Table 3 used in inverter, by the use of the $\mathrm{GaN}, \mathrm{SiC}$ and $\mathrm{Si}$ switches results are obtained. The following Table 5 shows the output parameters of the circuit using the different technologies.

Table 5: Simulation Results of the class $d \mathrm{~h}$ bridge inverter.

\begin{tabular}{|c|c|c|c|}
\hline Parameter & SI & SIC & GAN \\
\hline $\begin{array}{c}\text { Output } \\
\text { Voltage }\end{array}$ & $150 \mathrm{~V}$ & $150 \mathrm{~V}$ & $150 \mathrm{~V}$ \\
\hline $\begin{array}{c}\text { Output } \\
\text { Power }\end{array}$ & $1.35 \mathrm{KW}$ & $1.39 \mathrm{KW}$ & $1.08 \mathrm{KW}$ \\
\hline Efficiency & $62 \%$ & $68 \%$ & $71.1 \%$ \\
\hline
\end{tabular}

\subsection{Comparison of devices using ZVS Class E inverter topology}

In this section we are going to see the different devices Comparison of class e inverter topology. The Fig. 4 shows the typical class e inverter with series rlc resonant circuit.

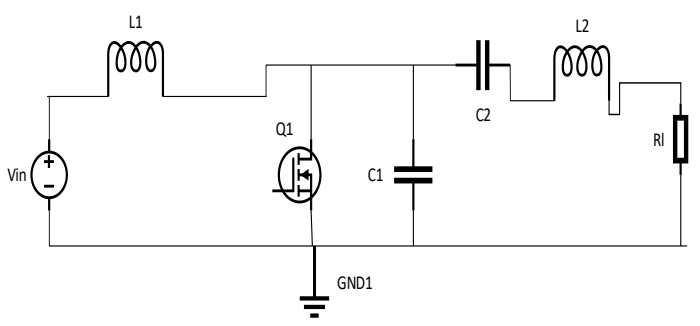

Fig 5: Class E inverter using different type of technologies.[2]

In this type of topology, the no of switches used are one. This consists of a series RLC resonant circuit in which the Resistor (Rl) is taken as the load. The Following Table VI shows the input circuit parameters of the inverter. In the table, the value of the shunt capacitor is varied according to the switch output capacitance $\left(\mathrm{C}_{\text {oss }}\right)$ so that the energy dissipated from the switch is stored in the capacitor.

The following Fig. 6 shows the modes of operation and the two modes of operation are during the time at which is in on position and off position. During the switch on position, the current passes through the switch to the load and during the off position, the energy stored in the shunt capacitor during the on position is passes to load.

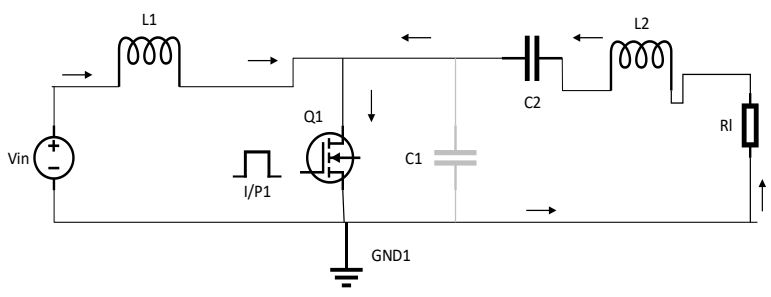

Fig 6(a): During the switch on position.

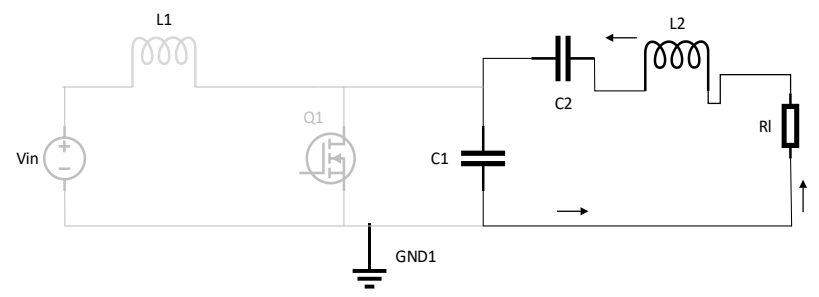

Fig 6(b): During the switch off position.

Table 6: Input Parameters of the Class E Inverter.

\begin{tabular}{|c|c|c|}
\hline Parameter & Value & Description \\
\hline Vin & $170 \mathrm{~V}$ & Input dc voltage \\
\hline $\mathrm{f}_{0}$ & $13.56 \mathrm{MHz}$ & Switching frequency \\
\hline $\mathrm{L}_{1}$ & $1 \mu \mathrm{H}$ & Input inductor \\
\hline $\mathrm{C}_{1}(\mathrm{GaN})$ & $49 \mathrm{pF}$ & Shunt capacitor \\
\hline $\mathrm{C}_{1}(\mathrm{SiC})$ & $2.7 \mathrm{pF}$ & Shunt capacitor \\
\hline $\mathrm{C}_{1}(\mathrm{Si})$ & $45 \mathrm{pF}$ & Shunt capacitor \\
\hline $\mathrm{R}_{\mathrm{L}}$ & $11.5 \Omega$ & Output Load \\
\hline $\mathrm{C}_{2}$ & $113 \mathrm{pF}$ & Capacitor \\
\hline $\mathrm{L}_{2}$ & $1445 \mathrm{nH}$ & Inductor \\
\hline
\end{tabular}

The Fig. 8 shows the voltage and current across the switch ( $\mathrm{GaN}, \mathrm{SiC}, \mathrm{Si}$ ) and across capacitor, the output voltage and output current of the load. The following table 7 represents the values of the voltages and currents at different switches of $\mathrm{GaN}, \mathrm{SiC}, \mathrm{Si}$ and at the capacitor in the circuit.

Table 7: Voltage and Current at different points of inverter.

\begin{tabular}{|c|c|c|c|}
\hline Parameter & SI & SIC & GAN \\
\hline Voltage of Switch Q1 & $1.1 \mathrm{kV}$ & $1.1 \mathrm{KV}$ & $1 \mathrm{KV}$ \\
\hline Current of Switch Q1 & $21 \mathrm{~A}$ & $22 \mathrm{~A}$ & $20 \mathrm{~A}$ \\
\hline $\begin{array}{c}\text { Voltage of Capacitor } \\
\text { C1 }\end{array}$ & $1.1 \mathrm{KV}$ & $1.1 \mathrm{KV}$ & $1 \mathrm{KV}$ \\
\hline $\begin{array}{c}\text { Current of Capacitor } \\
\text { C1 }\end{array}$ & $9 \mathrm{~A}$ & $12 \mathrm{~A}$ & $9 \mathrm{~A}$ \\
\hline Output Voltage & $160 \mathrm{~V}$ & $167 \mathrm{~V}$ & $170 \mathrm{~V}$ \\
\hline Output Current & $14 \mathrm{~A}$ & $1 \mathrm{~A}$ & $15 \mathrm{~A}$ \\
\hline
\end{tabular}

The simulation of the soft switching single phase h-bridge inverter is done and following are the results.

Table 8: Simulation Results of Class E Inverter.

\begin{tabular}{|c|c|c|c|}
\hline Parameter & SI & SIC & GAN \\
\hline $\begin{array}{c}\text { Output } \\
\text { Voltage }\end{array}$ & $160 \mathrm{~V}$ & $167 \mathrm{~V}$ & $170 \mathrm{~V}$ \\
\hline Output Power & $1.004 \mathrm{KW}$ & $1.03 \mathrm{KW}$ & $1.08 \mathrm{KW}$ \\
\hline Efficiency & $93.6 \%$ & $85 \%$ & $96 \%$ \\
\hline
\end{tabular}

The results of class $\mathrm{E}$ are obtained as from Table 8. As clearly, the GaN switch produces more output power and the efficiency is more than the $\mathrm{SiC}$ and $\mathrm{Si}$. 


\section{Simulation Results Of Class D Inverter Topology}

In this section we are going to present the simulation results i.e wave forms of the zvs based class $d$ inverter using $\mathrm{GaN}, \mathrm{SiC}, \mathrm{Si}$.

\subsection{Class d inverter using GaN switch}

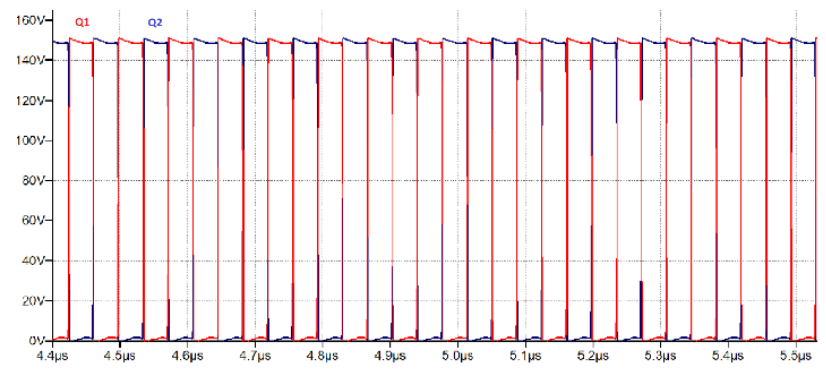

Fig 7(a): Voltage across the switch Q1 and Q2 of class d inverter $(\mathrm{GaN})$.

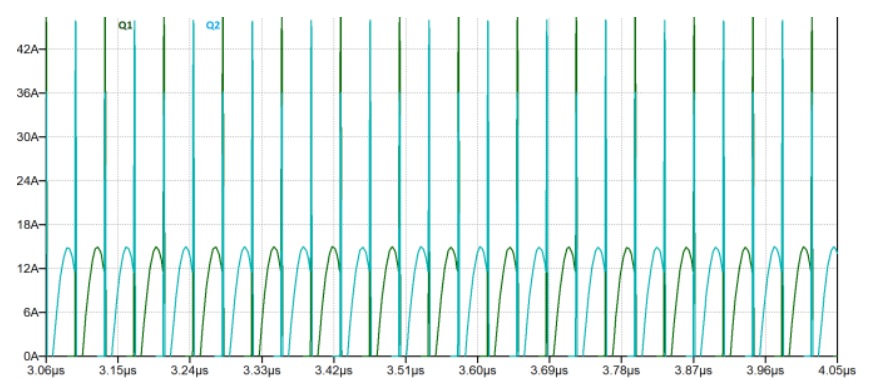

Fig 7(b): Current flowing in the switch Q1 and Q2 of class d inverter $(\mathrm{GaN})$.

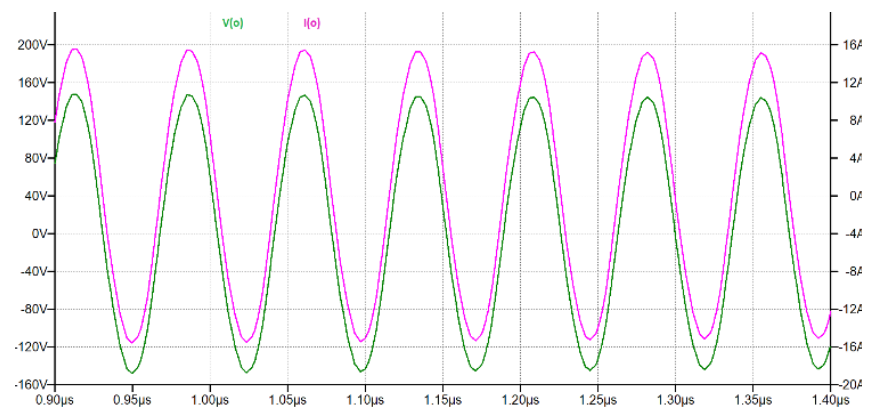

Fig 7(c): Output Voltage and Output Current across load of class d inverter $(\mathrm{GaN})$.

The Figs. 7(a), 7(b), 7(c) shows the voltage and current waveforms of the class d inverter using the GaN switch. The Fig. 7(a) and the table 4 represents the voltage of the switches Q1 and Q2 with respect to the time. The Fig. 7(b) and the table represents the waveform and the values of the current at switches Q1 and Q2. The Fig. 7(c) represents the output voltage and the output current of the class $\mathrm{d}$ inverter across the load and the values are given in the table 4 .

\subsection{Class d inverter using SiC switch}

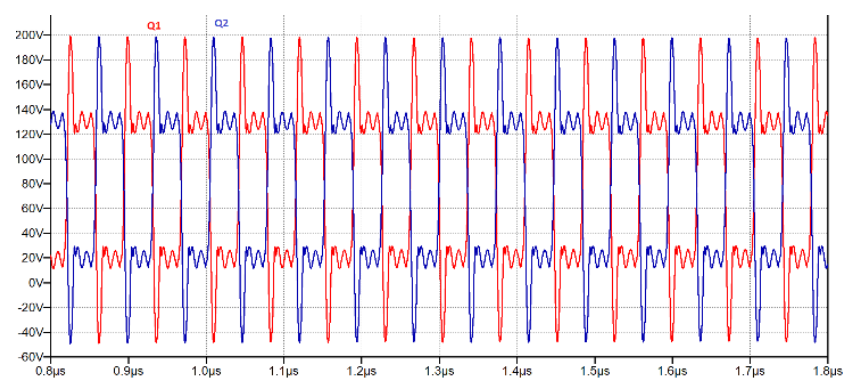

Fig 8(a): Voltage across the switch Q1 and Q2 of class d inverter (SiC).

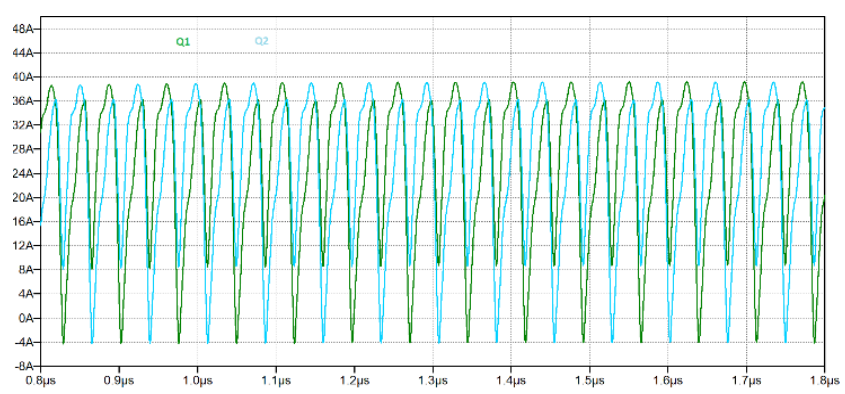

Fig 8(b): Current flowing in the switch Q1 and Q2 of class d inverter $(\mathrm{SiC})$.

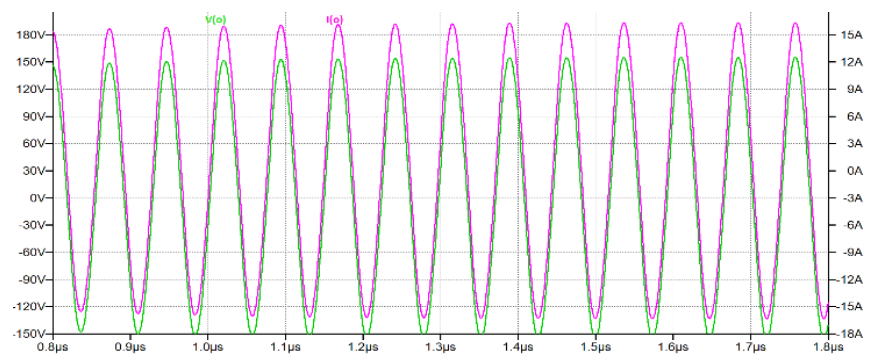

Fig 8(c): Output Voltage and Output Current through load of class d inverter $(\mathrm{SiC})$.

The Figs. 8(a), 8(b), 8(c) shows the voltage and current waveforms of the class d inverter using the $\mathrm{SiC}$ switch. The Fig. 8(a) and the table 4 represents the voltage of the switches Q1 and Q2 with respect to the time. The Fig. 8(b) and the table represents the waveform and the values of the current at switches Q1 and Q2. The Fig. 8(c) represents the output voltage and the output current of the class d inverter across the load and the values are given in the table 4 .

\subsection{Class d inverter using Si switch}

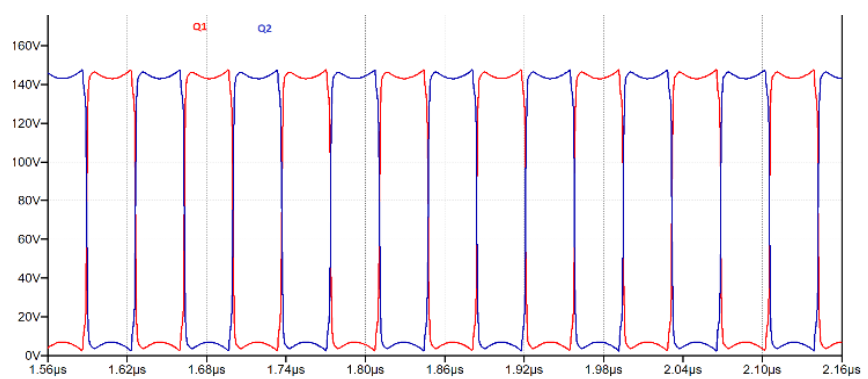

Fig 9(a): Voltage across the switch Q1 and Q2 of class d inverter (Si). 


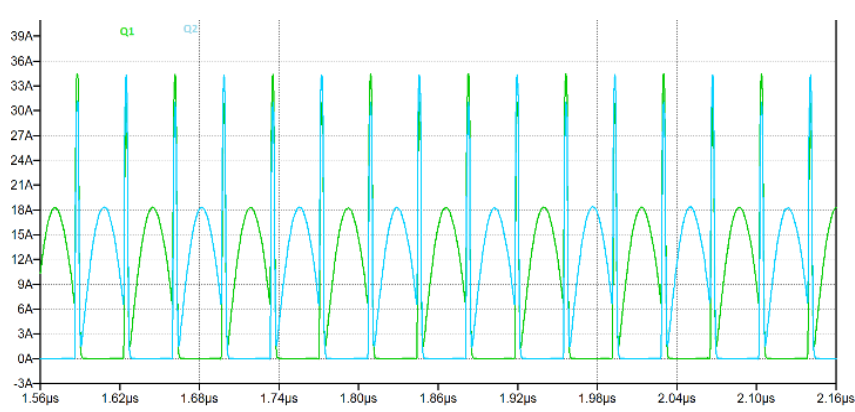

Fig 9(b): Current flowing in the switch Q1 and Q2 of class d inverter $(\mathrm{Si})$.

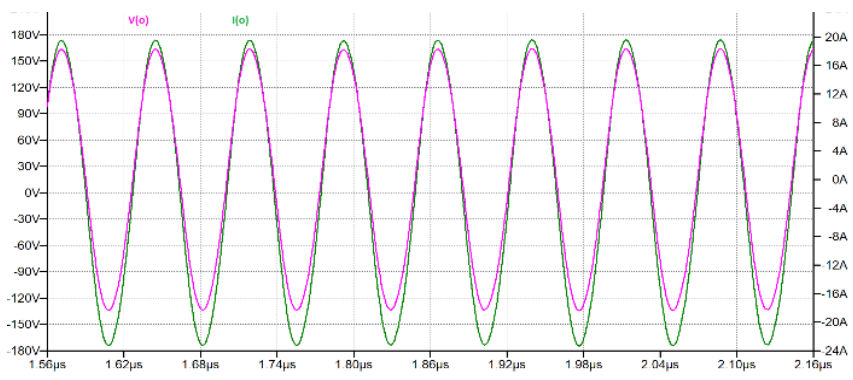

Fig 9(c): Output Voltage and Output Current through the load of class d inverter $(\mathrm{Si})$.

The Figs. 9(a), 9(b), 9(c) shows the voltage and current waveforms of the class $d$ inverter using the Si switch. The Fig. 9(a) and the table 4 represents the voltage of the switches Q1 and Q2 with respect to the time. The Fig. 9(b) and the table represents the waveform and the values of the current at switches Q1 and Q2. The Fig. 9(c) represents the output voltage and the output current of the class d inverter across the load and the values are given in the table 4 .

\section{Simulation Results of Class E Inverter Topology}

In this section we are going to present the simulation results i.e wave forms of the zvs based class e inverter using GaN, SiC, Si.

\subsection{Class e inverter using GaN switch}

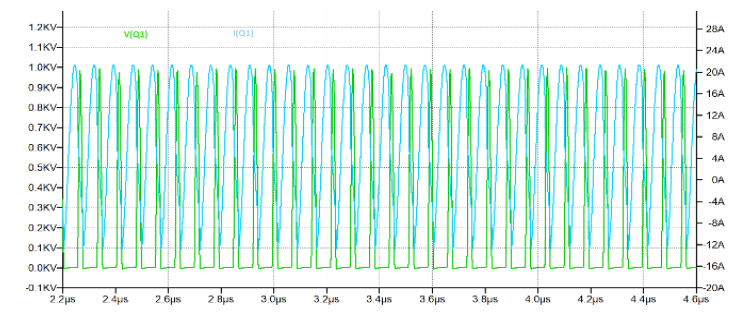

Fig 10(a): Voltage and Current across the switch Q1 of class e inverter $(\mathrm{GaN})$.

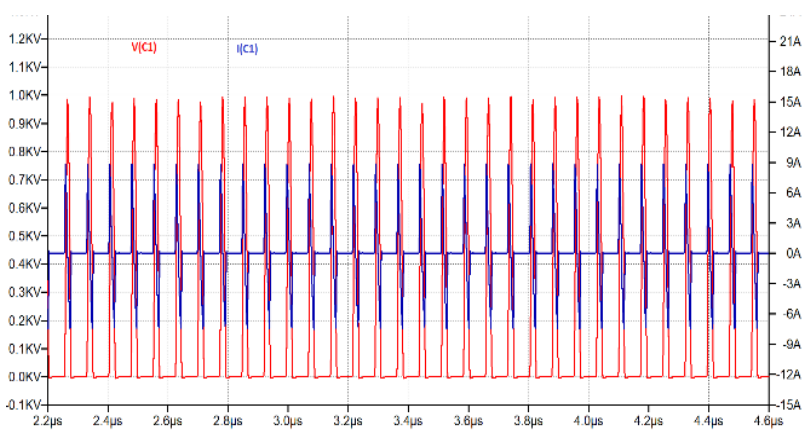

Fig 10(b): Voltage and Current across the capacitor $\mathrm{C} 1$ of class e inverter $(\mathrm{GaN})$.

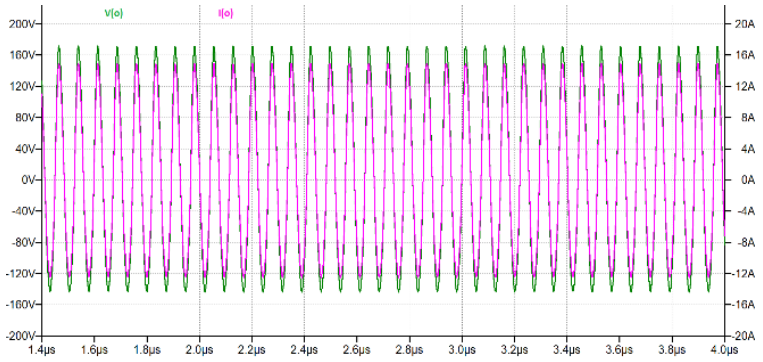

Fig 10(c): Output Voltage and Output Current through load of class e inverter $(\mathrm{GaN})$.

The Figs. 10(a), 10(b), 10(c) represents the voltage and currents at the switch and the capacitor of the class e inverter. The switch used here is GaN. The Fig. 10(a) represents the waveforms of voltage and current with respect to the time of the switch Q1. The Fig. 10(b) represents the waveforms of the voltage and current at the capacitor $\mathrm{C} 1$. The Fig. 10(c) represents the waveforms of the output voltage and the output current of the class e inverter. The table 6 shows the numerical values of the voltage and currents of the circuit at the switch Q1 and capacitor $\mathrm{C} 1$.

\subsection{Class e inverter using SiC switch}

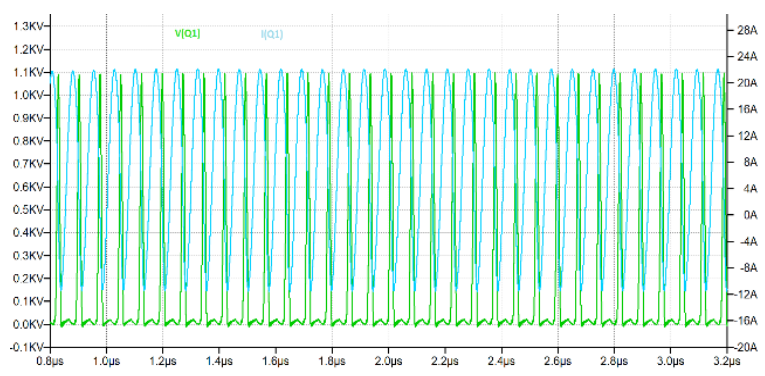

Fig 11(a): Voltage and Current across the switch Q1 of class e inverter $(\mathrm{SiC})$. 


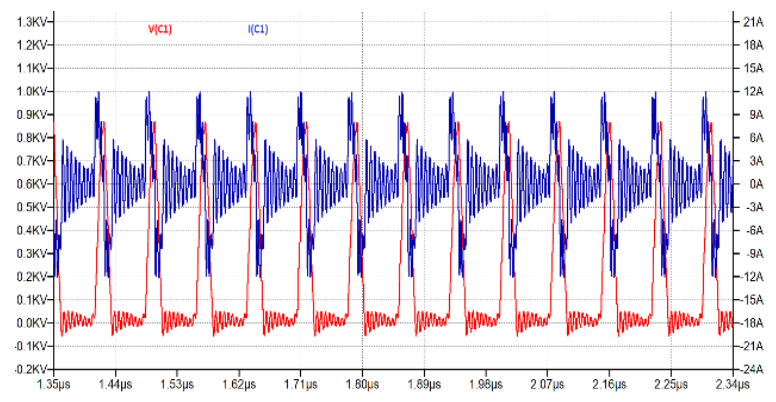

Fig 11(b): Voltage and Current across the capacitor $\mathrm{C} 1$ of class e inverter $(\mathrm{SiC})$.

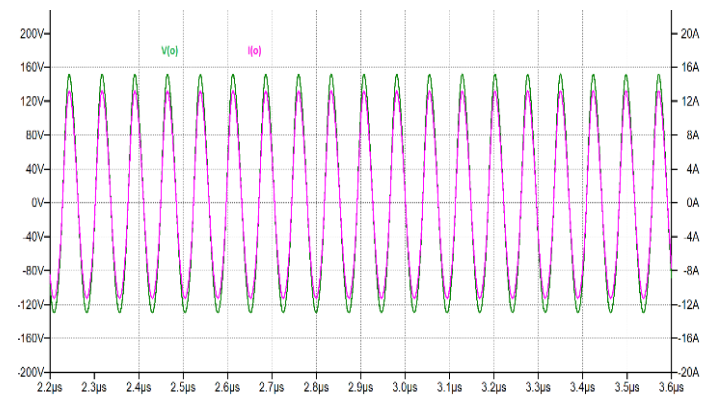

Fig 11(c): Output Voltage and Output Current across load of class e inverter ( $\mathrm{SiC})$.

The Figs. 11(a), 11(b), 11(c) represents the voltage and currents at the switch and the capacitor of the class $\mathrm{e}$ inverter. The switch used here is SiC. The Fig. 10(a) represents the waveforms of voltage and current with respect to the time of the switch Q1. The Fig. 10(b) represents the waveforms of the voltage and current at the capacitor C1. The Fig. 10(c) represents the waveforms of the output voltage and the output current of the class e inverter. The table 6 shows the numerical values of the voltage and currents of the circuit at the switch Q1 and capacitor $\mathrm{C} 1$.

\subsection{Class e inverter using Si switch}

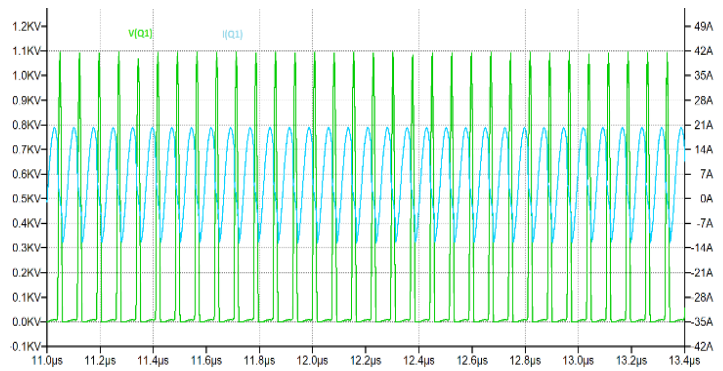

Fig 12(a): Voltage and Current across switch Q1 of class e inverter $(\mathrm{Si})$.

The Figs. 12(a), 12(b), 12(c) represents the voltage and currents at the switch and the capacitor of the class e inverter. The switch used here is $\mathrm{Si}$. The Fig. 12(a) represents the waveforms of voltage and current with respect to the time of the switch Q1. The Fig. 12(b) represents the waveforms of the voltage and current at the capacitor $\mathrm{C} 1$. The Fig. 12(c) represents the waveforms of the output voltage and the output current of the class e inverter. The table 6 shows the numerical values of the voltage and currents of the circuit at the switch Q1 and capacitor $\mathrm{C} 1$.

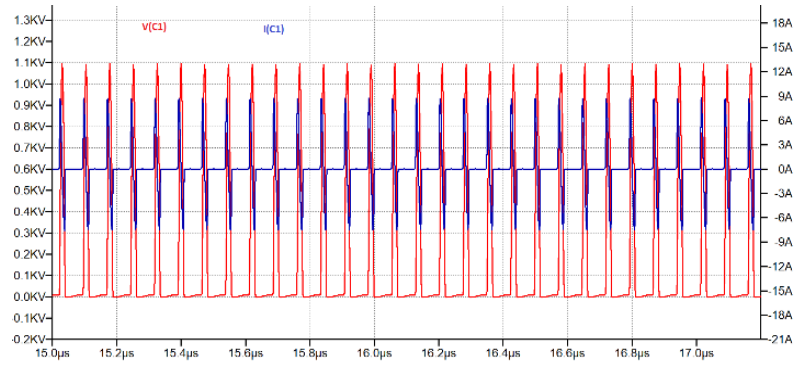

Fig 12(b): Voltage and Current across capacitor of class e inverter $(\mathrm{Si})$.

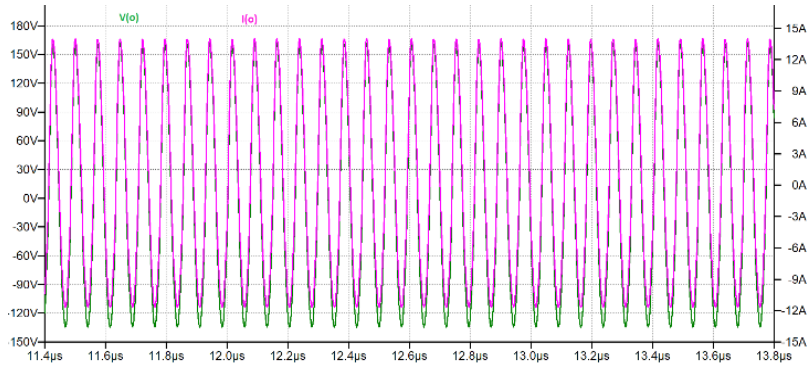

Fig 12(c): Output Voltage and Output Current across load of class e inverter $(\mathrm{Si})$.

\section{Conclusion}

In this paper, the comparison of different types of technologies of class $d$ and class e inverter are done and the simulation results are obtained for the use of converters which consists of different technology of GaN, SiC and Si. The output power of the inverter greater than $1 \mathrm{kw}$ for a switching frequency of $13.56 \mathrm{MHz}$ is obtained. The efficiency of the GaN technology used inverters are more efficient compared than that of $\mathrm{SiC}$ and $\mathrm{Si}$.

\section{References}

1. H. Tebianian, Y. Salami, B. Jeyasurya and J. E. Quaicoe, "A 13.56-MHz Full-Bridge Class-D ZVS Inverter With Dynamic Dead-Time Control for Wireless Power Transfer Systems," in IEEE Transactions on Industrial Electronics, vol. 67, no. 2, pp. 1487-1497, Feb. 2020.

2. S. Aldhaher, D. C. Yates and P. D. Mitcheson, "LoadIndependent Class E/EF Inverters and Rectifiers for $\mathrm{MHz}-$ Switching Applications," in IEEE Transactions on Power Electronics, vol. 33, no. 10, pp. 8270-8287, Oct. 2018.

3. K. Peng and E. Santi, "Class E resonant inverter optimized design for high frequency $(\mathrm{MHz})$ operation using eGaN HEMTs," 2015 IEEE Applied Power Electronics Conference and Exposition (APEC), Charlotte, NC, 2015, pp. 2469-2473.

4. Rodríguez-Benítez, Oscar \& Ponce-Silva, Mario \& Hernandez, Leobardo \& Aqui, Juan \& ClaudioSanchez, Abraham \& Calzada-Lara, G. \& Cortes, Claudia. (2018). Recent Advance and Future Progress 
of GaN Power Semiconductor Devices Used in PV Module Integrated Converters. 10.20944/preprints201812.0072.v1.

5. M. Kavitha, D. Prasad and P. B. Bobba, "Methods for overcoming misalignment effects control of dynamic wireless electric vehicle charging system," in IET Electric Power Applications, vol. 13,no. 8, pp. 1184$1192,82019$.

6. Srinivas Rao J., Srinivasa Varma, P., Suresh Kumar. $\mathrm{T}$, "Novel switching design structure for three phase 21-level multilevel inverter fed BLDC drive application," International Journal of Power Electronics and Drive Systems, 9(3), 2018

7. B. J. Varghese and P. B. Bobba, "Design and analysis of a robust system for wirelessly powering implantable devices," 2016 IEEE $1^{\text {st }}$ International Conference on Power Electronics , Intelligent Control and Energy Systems (ICPEICIES), Delhi, 2016, pp. 15.

8. M. Kavitha, P. B. Bobba and D.Prasad, "Effect of coil geometry and sheildig on wireless power transfer system," 2016 IEEE 7th Power India International Conference (PIICON), Bikaner, 2016, pp. 1-6.

9. Chow, Tat-Sing \& Guo, Zhibo. (2019). GaN smart power devices and integrate circuits. 10.1016/B9780-08-102306-8.00005-8. 